\title{
Price Discovery Study of Chinese ADRs on Global Markets
}

\author{
Yongli Luo", , Changxian Lan ${ }^{2}$ \\ ${ }^{1}$ College of Business, Houston Baptist University, Houston, United States \\ ${ }^{2}$ Management College, Beijing Union University, Beijing, China \\ *Corresponding author: yluo@hbu.edu, gltchangxian@buu.edu.cn
}

\begin{abstract}
This paper analyzes the price discovery mechanism between the Chinese American Depository Receipts (ADRs) listed on the New York Stock Exchange (NYSE) and their underlying H shares on the Hong Kong Stock Exchange (HKEX). It employs the Permanent-Transitory decomposition in vector autoregression (VAR) model, and finds that the New York stock market makes the principal contribution to the price discovery, and the proportion of contribution is $84.84 \%$; while the Hong Kong market makes only subsidiary contribution of $15.16 \%$. In addition, it confirms the existence of the long-term cointegration relationship between ADRs and $\mathrm{H}$ shares, which implies that portfolio diversification among Chinese ADRs is consistent with Global Center Hypothesis and efficient for international investors.
\end{abstract}

Keywords: Chinese ADRs, price discovery, permanent transitory decomposition

Cite This Article: Yongli Luo, and Changxian Lan, "Price Discovery Study of Chinese ADRs on Global Markets." Journal of Finance and Economics, vol. 6, no. 1 (2018): 32-37. doi: 10.12691/jfe-6-1-5.

\section{Introduction}

It is well recognized that listing American Depository Receipts (ADRs) in the U.S. market provides an important source of foreign capital investment for foreign enterprises, as well as an important instrument of portfolio diversification for international investors. With China's entry into the World Trade Organization (WTO) and its continuing financial liberalization reforms, more and more Chinese enterprises have taken their steps into the overseas capital markets. Since Sinopec Shanghai Petrochemical listed the first Chinese ADR on the New York Stock Exchange (NYSE) in 1993, China has become the 6th largest foreign country to list ADRs in the U.S. market. As of June, 2009, total 148 Chinese ADRs listed in the U.S. market (see J. P. Morgan ADR universe, Jun. 2009), among them, 38 listed on the NYSE, 31 traded on NASDAQ, 67 were on OTC and 12 were under $144 \mathrm{~A}$. Therefore, it is no denying that Chinese ADRs will eventually be of an important instrument for international portfolio diversification.

This paper concentrates on the Chinese ADRs listed on the NYSE with underlying stocks on Hong Kong Exchange (HKEX). The objective of this study is to determine which market makes the major contributions to the price discovery between the ADRs and their underlying stocks. The hypothesis is that ADR/stock price is a combined reflection of both the host market and the foreign market, and is mainly determined by the global financial market (also called Global Center Hypothesis). To effectively evaluate this hypothesis, we employ a permanent and transitory model to test how the host and foreign market contribute to the price discovery.
Accordingly, we select 15 ADRs and collect their weekly data to formulate into two portfolio assets. Then, we use econometric approaches to detect the leadership effects between the two cointegrated markets.

The results show that the U.S. market makes the principal contribution to the price discovery, and the average proportion contributed is $84.84 \%$, while the Hong Kong market makes the subsidiary contribution to the price discovery and the average proportion is $15.16 \%$. In addition, it confirms the existence of the long-term cointegration relationship between ADRs and $\mathrm{H}$ shares. The results are consistent with Global Center Hypothesis and have important implications for the portfolio diversification benefits of the international investors.

\section{Literature Review}

The price discovery study has been widely applied in financial market research, especially in cointegrated stocks or other financial equities. Fama and French [1] are the initiators to use permanent and temporary components method (or PT method) to examine the correlation structure of the prices in international stock markets. More recently, a few scholars begin to adopt this methodology into ADR market. However, it is arguing that whether the local or international market makes the principal contribution to price discovery. Kim et al. [2] find that the most influential factor in pricing the ADRs in Japan, UK, Sweden, Netherlands and Australia is their underlying shares. Additionally, based on a study of 113 ADRs from eight countries during the 1980-1994 period, Jiang [3] reports that the effect of the ADRs on local market portfolio is significant, although the ADR returns are 
significantly correlated with the U.S. returns, and they are affected by local market conditions and exchange rates. More over, Bacidore and Sofianos [4] confirm that the price discovery was determined in their home country. The similar results are also documented by Alaganar and Bhar [5], they examine the Australian ADRs, and find that the ADRs have a low correlation with the U.S. stock returns, offering diversification benefits. On the other hand, using data of 123 ADRs listed in 16 countries and employing the seemingly unrelated regression (SUR) approach, Patro [6] reports significant exposure of the ADRs returns to their respective home market portfolios, and the movements in the world market portfolio are found to be a significant determinant of the ADRs' returns. Simultaneously, using weekly data from 1990 to 1996, Choi and Kim [7] investigate 87 ADRs and find that the underlying, host, and local markets are all important determinants of the ADRs. The relative importance of these markets is found to be dependent on market types (emerging or industrial countries).

Very few research has been done in Chinese ADRs, especially on the mechanism of price discovery study. The research most closely related to this study is undertaken by $\mathrm{Xu}$ and Fung [8], they use multivariate GARCH model and examine the information flow between the Hong Kong and New York stock market. specifically, Kutan and Zhou [9] conduct an empirical study on Chinese ADRs and report that the underlying Hong Kong market has the most significant impact on mean returns of the ADRs, their findings are consistent with those of Kim, et al. [2] However, by using information share model, $\mathrm{Su}$ and Chong [10] further examine the cross-listed Chinese stocks in the New York and Hong Kong market, they suggest that the stock prices of these two exchanges are cointegrated and mutually adjusted. More over, their results reveal that the local market contributes more than the host market to the mechanism of information flow.

Following the spirit of previous research, we attempt to provide empirical results based on the permanent-transitory decomposition in Vector Autoregression (VAR) model.
The VAR model is superior in capturing a combined price reflecting the common factors and unique factors arising from both the NYSE and the HKEX, given the efficient hypothesis of financial market and information transparency between the different markets. The assumption is that, for the same company, the price of ADR and its underlying stock is determined by the information flow from each or both of the two markets. To achieve our goal, we collect the weekly data of the Chinese ADRs and their underlying H stocks over the period from 2005 to 2008, then we formulate them into two portfolios and apply an econometric VAR model to analyze the price discovery mechanism.

\section{Data and Methodology}

\subsection{Data}

In this paper, we only focus on those Chinese ADRs listed on the NYSE with underlying $\mathrm{H}$ shares on HKEX. Correspondingly, we collect their weekly price data (adjusted) from the Center for Research in Security Prices (CRSP) and the China Center for Economic Research (CCER) over the period of January 1, 2005 to December 31, 2008. The ADRs are distributed in eight different industry sectors: Chemicals, Travel and Leisure, Telecommunication, Oil and Gas Producers, Mining, Electricity, Insurance, and Semiconductor. Based on the weekly price series, we simply generate two equally weighted portfolios. One is the ADR portfolio and the other one is the underlying stock portfolio, each portfolio consists of 15 companies. In order to measure the two portfolios at the same unit, the underlying stock prices (measured by Hong Kong dollars) are converted into the U.S. dollar prices based on the weekly HKD/USD foreign exchange rates. Finally, we obtain two portfolios of $\mathrm{Z}_{1 \mathrm{t}}$ and $\mathrm{Z}_{2 \mathrm{t}}$, which are expressed as logarithm form of the equally weighted portfolio of underlying $\mathrm{H}$ shares and the portfolio of ADRs. The general description of the sample firms is shown in Table 1 .

Table 1. Description of Chinese ADRs listed on the NYSE

\begin{tabular}{|c|c|c|c|c|c|}
\hline ADR issued by & Ticker & Underlying & Ratio & Industry & Eff. Date \\
\hline Sinopec Shanghai Petrochemical & SHI & 0338.HK & $1: 100$ & Chemicals & 23-Jul-93 \\
\hline Guangshen Railway & GSH & 0525.HK & $1: 50$ & Travel \& Leisure & 16-May-96 \\
\hline China Eastern Airlines & CEA & 0670.HK & $1: 100$ & Travel \& Leisure & 30-Jan-97 \\
\hline China Southern Airlines & $\mathrm{ZNH}$ & 1055.HK & $1: 50$ & Travel \& Leisure & 24-Jul-97 \\
\hline China Mobile & CHL & 0941.HK & $1: 5$ & Telecom. & 16-Oct-97 \\
\hline Yanzhou Coal Mining & YZC & 1171.HK & $1: 10$ & Mining & 27-Mar-98 \\
\hline PetroChina & PTR & 0857.HK & $1: 100$ & Oil \& Gas Producers & 30-Mar-00 \\
\hline China Unicom (Hong Kong) Limited & $\mathrm{CHU}$ & 0762.HK & $1: 10$ & Telecom. & 16-Jun-00 \\
\hline China Petroleum \& Chemical & SNP & 0386.HK & $1: 100$ & Oil \& Gas Producers & 18 -Oct-00 \\
\hline China National Offshore Oil-CNOOC & CEO & 0883.HK & $1: 100$ & Oil \& Gas Producers & 20-Feb-01 \\
\hline Aluminum Corporation of China & $\mathrm{ACH}$ & 2600.HK & $1: 25$ & Mining & 5-Dec-01 \\
\hline China Telecom & CHA & 0728.HK & $1: 100$ & Telecom. & 6-Nov-02 \\
\hline Huaneng Power International & HNP & 0902.HK & $1: 40$ & Electricity & 19-Aug-03 \\
\hline China Life Insurance & LFC & 2628.HK & $1: 15$ & Insurance & 17-Dec-03 \\
\hline Semiconductor Manufacturing International & SMI & 0981.HK & $1: 50$ & Semiconductor & 18-Mar-04 \\
\hline
\end{tabular}

Data sources: http://www.adrbny.com, http://www.adr.com. and http://www.hkex.com.hk/index.htm. 
Noticed that two simple portfolios are generated to represent the equally weighted ADRs prices and their equally weighted underlying stock price. The specific calculation is shown as follows:

$$
P_{h}^{\prime}=\frac{P_{h}}{\text { Ratio }} \times R_{U S D} / H K D
$$

Where, $\mathrm{P}_{\mathrm{h}}$ ' is the converted $\mathrm{H}$ share price, $\mathrm{P}_{\mathrm{h}}$ is the $\mathrm{H}$ share price at HKEX, Ratio is the number of $\mathrm{H}$ shares that one unit of ADR can be converted to. $\mathrm{R}_{\mathrm{USD} / \mathrm{HKD}}$ is the weekly adjusted closing price of the HKD/USD exchange rate.

\subsection{Methodology}

Gonzalo and Granger [11] demonstrate that the cointegrated system $\left(Z_{i t}\right)$ can be represented by the sum of a permanent component $C_{t}$ and a transitory component $u_{t}$, which is also known as Permanent-Transitory (P-T) model. This decomposition can distinguish between long-term component and short-term cycles of securities or exchange markets. Thus, assuming the ADR market is cointegrated with their underlying stock market, we apply the P-T model to decompose the mechanism of ADR price discovery system. Let $Z_{t}$ be a vector containing an underlying stock portfolio price series $\left(Z_{1 t}\right)$, and an ADR portfolio price series $\left(\mathrm{Z}_{2 t}\right)$; both series are in logarithm form, then we have:

$$
\Delta Z_{t}=\beta^{\prime} Z_{t}=Z_{1 t}-Z_{2 t}, \quad \beta=(1,-1)^{\prime} .
$$

If the long run cointegration relationship is supported, we can represent $Z_{t}$ by a vector-error correction (VEC) model as following Equation (3):

$$
\Delta Z_{t}=\alpha \beta^{\prime} Z_{t-1}+\sum_{i=1}^{n} \Gamma_{i} \Delta Z_{t-i}+\varepsilon_{t}
$$

where, $\Delta$ is the first-difference operator, $\beta$ is the coefficient matrix of cointegrating vectors, $\alpha$ is an adjustment coefficient matrix, $\Gamma_{i}$ is a matrix of the estimated parameters reflecting short-run dynamics, and $\varepsilon_{\mathrm{t}}$ is a white-noise error vector.

Because $\Gamma$ is perpendicular to the absolute value of $\alpha$, the contribution to price discovery of each market can be represented by the coefficient of the common factor in each portfolio. The larger the weight is, the bigger the contribution that market makes. Therefore, the proportion of the Hong Kong market's contribution $\left(\mathrm{S}_{1}\right)$ and that of the New York market $\left(\mathrm{S}_{2}\right)$ can be expressed as:

$$
S_{1}=\gamma_{1} / \sum \gamma_{i}, \text { and } S_{2}=\gamma_{2} / \sum \gamma_{i}, i=1,2 \text {. }
$$

\section{Empirical Results}

\subsection{Unit Root Test}

Granger and Newbold [12] show that a spurious regression problem could be encountered studying with non-stationary series. In this case, the results obtained by regression analysis do not reflect the accurate and real relationship. The most common used tests in literature determining the stationarity levels of series are Unit Root test by Augmented Dick-Fuller (ADF) test [13] and PP test [14]. Correspondingly, we conduct the ADF and PP tests and present the results as follows in Table 2.

According to the ADF and PP unit root tests in Table 2Panel $A$, the t-value for $Z_{1 t}$ generated by the above regression model corresponding to the ADF test is -0.589 , and PP test is -0.614 . The t-value for $Z_{2 t}$ generated by the above regression model corresponding to the ADF test is -0.617 , and PP test is -0.656 , which are greater than the critical values of $-2.57,-1.94$, and -1.62 at the $1 \%, 5 \%$, $10 \%$ significant levels, respectively. We fail to reject the null hypothesis and conclude that both the $\mathrm{Z}_{1 \mathrm{t}}$ series and $\mathrm{Z}_{2 \mathrm{t}}$ series are non-stationary processes.

According to the unit root test results on the $1^{\text {st }}$ difference series in Table 2--Panel $B$, the $t$-value for $R_{1 t}$ series generated by the above regression model corresponding to the ADF test is -12.341 , and the PP test is -12.325 . The $t$-value for $R_{2 t}$ series generated by the above regression model corresponding to the ADF test is -12.463 , and the PP test is -12.462 , which is smaller than the critical values of $-3.46,-2.87$, and -2.57 at the $1 \%, 5 \%$, $10 \%$ significant level, respectively). We reject the null hypothesis and conclude that the $R_{1 t}$ series and $R_{2 t}$ series

\begin{tabular}{|c|c|c|c|c|c|c|c|}
\hline \multicolumn{4}{|c|}{ HO: $Z_{\text {It }}$ has a unit root } & \multicolumn{4}{|c|}{ HO: $Z_{2 t}$ has a unit root } \\
\hline \multicolumn{2}{|c|}{ ADF test } & \multicolumn{2}{|c|}{ PP test } & \multicolumn{2}{|c|}{ ADF test } & \multicolumn{2}{|c|}{ PP test } \\
\hline t-Stat & Prob & t-Stat & Prob & t-Stat & Prob & t-Stat & Prob \\
\hline-2.323 & 0.419 & -2.373 & 0.392 & -2.351 & 0.405 & -2.382 & 0.388 \\
\hline $\mathrm{t}$ critical & $1 \%$ lev & -4. & & & & level & -3.139 \\
\hline
\end{tabular}
are both stationary processes at the first difference.

Table 2. Unit Root Test

\begin{tabular}{|c|c|c|c|c|c|c|c|}
\hline \multicolumn{4}{|c|}{$H O: R_{I t}$ has a unit root } & \multicolumn{4}{|c|}{$H O: R_{2 t}$ has a unit root } \\
\hline \multicolumn{2}{|c|}{ ADF test } & \multicolumn{2}{|c|}{ PP test } & \multicolumn{2}{|c|}{$\mathrm{ADF}$ test } & \multicolumn{2}{|c|}{ PP test } \\
\hline t-Stat & Prob & t-Stat & Prob & t-Stat & Prob & t-Stat & Prob \\
\hline-14.243 & 0.000 & -14.319 & 0.000 & -14.342 & 0.0000 & -14.385 & 0.000 \\
\hline$t$ critical & $1 \%$ level & $-4 .(1$ & & & & level & -3.139 \\
\hline
\end{tabular}

Panel A: ADF and PP test on levels

Panel B: ADF and PP test on first differences

Note: 1) $\mathrm{R}_{1 \mathrm{t}}$, represent the $1^{\text {st }}$ difference of price of $\mathrm{H}$ share portfolio, $\mathrm{R}_{2 \mathrm{t}}$ represent the $1^{\text {st }}$ difference of the price of ADR portfolio; 2 ) Lag Length is automatically based on Schwarz Information Criterion (SIC), MAXLAG=14. 3) None Exogenous 4) PP test is automatic selection based on NeweyWest Bandwidth. 5) With intercept and trend; 6) Prob is MacKinnon (1996) [15] one-sided p-values. 
Table 3. Johansen Cointegration Test

Panel A: Unrestricted Cointegration Rank Test (Trace)

\begin{tabular}{|c|c|c|c|c|}
\hline $\begin{array}{c}\text { Hypothesized } \\
\text { No. of CE(s) }\end{array}$ & Eigenvalue & $\begin{array}{c}\text { Trace } \\
\text { Statistic }\end{array}$ & $\begin{array}{c}0.05 \\
\text { Critical Value }\end{array}$ & Prob.** \\
\hline None $*$ & 0.069 & 15.992 & 15.495 & 0.042 \\
\hline At most 1 & 0.006 & 1.296 & 3.841 & 0.255 \\
\hline
\end{tabular}

Panel B: Unrestricted Cointegration Rank Test (Maximum Eigenvalue)

\begin{tabular}{|c|c|c|c|c|}
\hline $\begin{array}{c}\text { Hypothesized } \\
\text { No. of CE(s) }\end{array}$ & Eigenvalue & Max-Eigen Statistic & $\begin{array}{c}0.05 \\
\text { Critical Value }\end{array}$ & Prob.*** \\
\hline None & 0.069 & 14.696 & 14.265 & 0.043 \\
\hline At most 1 & 0.006 & 1.296 & 3.841 & 0.255 \\
\hline
\end{tabular}

Note: Trace test reports 1 cointegrating eiqenvalues at the 0.05 level; Max-eigenvalue test reports 1 cointegrating eigenvalues at the 0.05 level; * denotes rejection of the hypothesis at the 0.05 level; **MacKinnon-Haug-Michelis (1999) [16] p-values.

\subsection{Cointegration Test}

Once both ADR portfolio and $\mathrm{H}$ share portfolio are determined to be non-stationary at their level, we move further to examine the nature of their linear combination. Since we differentiate our sample series once, there is one unit root, so it is an I(1) process. Specifically, we will be interested in examining the linear combination between the non-stationary $\mathrm{Z}_{1 \mathrm{t}}$ series and $\mathrm{Z}_{2 \mathrm{t}}$ series, if such a linear combination exists, then $Z_{1 t}$ series and $Z_{2 t}$ series are said to be cointergrated. However, taking difference method does not only erase the effects of persistent shocks on the variable in the past periods, but also may erase the long term relationships besides the shocks. In this point, cointegration analysis says that even if economic variables are not stationary, there might still exist a linear combination of these series; if so, this might be modeled econometrically in the cointegration approach developed by Gonzalo and Granger [11]. The cointegration approach states that time series which are not stationary in level but stationary in their first difference may be modeled in their level without long term information loss. Therefore, we conduct the Johansen cointegration test [17] including the differences and levels of non-stationary time series. Accordingly, we present the testing results in Table 3.

According to the results in Table 3, one cointegration vector is detected for both trace and maximum eigenvalue statistics at the 5\% significance level. In other words, the null hypothesis, claiming there is no cointegration vector, is rejected according to the $t$ statistics. In conclusion, a long term relationship exists between the two portfolios.

\subsection{Vector Error Correction (VEC) Results}

Based on the VEC results [18], the cointegration equation can be described as:

$$
\mathrm{C}_{t}=0.6083-1.0503 Y_{t}+\mu_{t} \text {. }
$$

The empirical results from the VEC model are listed in Table 4 and Table 5:

Table 4. Vector Error Correction Estimates

\begin{tabular}{|c|c|c|}
\hline Cointegrating Eq: & CointEq1 & \\
\hline $\mathrm{H}(-1)$ & 1.0000 & \\
\hline \multirow[t]{3}{*}{$\operatorname{ADR}(-1)$} & -1.0503 & \\
\hline & $(0.0112)$ & \\
\hline & {$[-94.0113]$} & \\
\hline $\mathrm{C}$ & 0.6083 & \\
\hline Error Correction: & $\mathrm{D}(\mathbf{H})$ & D(ADR) \\
\hline \multirow[t]{3}{*}{ CointEq1 } & -0.4023 & -0.0719 \\
\hline & $(0.2332)$ & $(0.2006)$ \\
\hline & {$[-1.7255]$} & {$[-0.3584]$} \\
\hline \multirow[t]{3}{*}{$\mathrm{D}(\mathrm{H}(-1))$} & 0.5863 & 1.0574 \\
\hline & $(0.2377)$ & $(0.2045)$ \\
\hline & [ 2.4669] & [ 5.1701] \\
\hline \multirow[t]{3}{*}{$\mathrm{D}(\mathrm{ADR}(-1))$} & -0.4806 & -0.9677 \\
\hline & $(0.2606)$ & $(0.2242)$ \\
\hline & {$[-1.8439]$} & {$[-4.3156]$} \\
\hline \multirow[t]{3}{*}{$\mathrm{C}$} & -0.0578 & -0.0692 \\
\hline & $(0.1698)$ & $(0.1461)$ \\
\hline & {$[-0.3407]$} & {$[-0.4737]$} \\
\hline R-squared & 0.0440 & 0.1950 \\
\hline Adj. R-squared & 0.0202 & 0.1749 \\
\hline F-statistic & 1.8436 & 9.6915 \\
\hline Log likelihood & -472.6229 & -441.6424 \\
\hline Akaike AIC & 4.6468 & 4.3460 \\
\hline
\end{tabular}

Notes: 1) Total observations is 206 after adjustments.2) Standard errors are shown in parentheses and t-statistics are shown in square brackets.

Table 5. P-T model estimation and price discovery contribution

\begin{tabular}{|c|c|c|c|c|c|}
\hline \multirow{2}{*}{ Parameter } & Cointegration coefficient & \multicolumn{2}{|c|}{ Adjusted coefficient } & \multicolumn{2}{c|}{ Price discovery contribution } \\
\cline { 2 - 5 } & $\beta_{0}$ & $\alpha_{1}$ & $\alpha_{2}$ & $\mathrm{~S}_{1}$ & $\mathrm{~S}_{2}$ \\
\hline Results & 0.608309 & -0.402312 & -0.071900 & & \multirow{2}{*}{$15.16 \%$} \\
\hline Std errors & & $(0.23316)$ & $(0.20061)$ & $84.84 \%$ \\
\hline t-values & & {$[-1.72546]$} & {$[-0.35842]$} & & \\
\hline
\end{tabular}

Note: The standard errors and statistical $t$ values are shown in parentheses and square brackets, respectively; $\mathrm{S}_{1}, \mathrm{~S}_{2}$ are the proportion of price discovery contribution of the Hong Kong stock market and the New York stock market, respectively. 
According to the above results in Table 4 and Table 5, $\beta_{0}$ represents the transaction cost, in another word, the transaction cost of converting $\mathrm{H}$ share to ADRs is 0.6083 . The transaction costs include all the fees and foreign exchange premium during the process of conversion. Adjusted coefficient $\alpha_{1}$ and $\alpha_{2}$ reflect the adjusting speed of the Hong Kong market and New York market when the price is going far beyond the long term equilibrium price. $S_{1}(15.16 \%)$ and $S_{2}(84.84 \%)$ are the proportion of contribution to the price discovery by the Hong Kong market (the $C$ series) and the New York market (the $Y$ series), respectively. Therefore, we can safely present the price discovery results as shown in the following Equations 6 and 7.

$$
\begin{aligned}
\Delta C_{t}= & -0.0579-0.4023 \Delta Y_{t} \\
& +0.5863 \Delta C_{t-1}-0.4806 \Delta Y_{t-1} \\
\Delta Y_{t}= & -0.0692-0.0719 \Delta C_{t} \\
& +1.0573 \Delta Y_{t-1}-0.9677 \Delta C_{t-1} .
\end{aligned}
$$

\section{Conclusion}

This paper use P-T Model to analyze the price discovery mechanism of the Chinese ADRs listed on the NYSE and their underlying stocks listed on the HKEX. This study finds that the New York market makes the principal contribution to the price discovery, and the contribution proportion is $84.84 \%$, while the Hong Kong market makes subsidiary contribution to the price discovery, and the proportion of contribution is $15.16 \%$. This is consistent with the global center hypothesis [19]. Under the environment of global economy, the price volatility is affected by the common factors generated from the global financial market, and is also influenced by the information spread out to different local markets from the global financial center. Our result is of clear evidence that the international market is playing the leadership effects among the global financial markets [20]. Therefore, the results have important implications for the diversification benefits to international investors. In sum, the existence of the long term cointegration relationship between ADRs and their underlying $\mathrm{H}$ shares implies that employing portfolio diversification in Chinese ADRs would be efficient.

The result is contradicting to the home country hypothesis. A few scholars believe that domestic market should make the primary contribution to the price discovery of those dually listed securities on different markets, because most important information, such as returns, dividends, annual report, etc, are initially announced from the domestic market [21]. However, the results imply that the international market plays a leading role in price discovery. Therefore, for those overseas listed Chinese companies, the global market impacts and information must be greatly concerned even their businesses are not globalized. In another words, these Chinese ADR companies cannot assess their risks from an isolated domestic perspective.

Although the cash flows of those Chinese ADRs originate from China, but the price volatility and price cointergration between ADRs and $\mathrm{H}$ shares are mainly determined by the information from overseas market. The alternative explanation relies on the development of modern technology, especially, online information diminishes the arbitrage opportunities and information asymmetry between different markets [22]. Therefore, location is not a barrier for financial transaction any more. In summary, the NYSE plays a leading effect in price discovery depending on four determinants: first, the NYSE is a global financial center, the transaction volume and financial disclosure system allow firms to enjoy the advantages of greater liquidity, transparency and access to the US capital market [23]. Second, from the perspective of the US investors, investing foreign ADRs is a convenient way of obtaining global diversification. Moreover, most of the Chinese ADR firms listed on the NYSE are selected from the top business from China, and also their businesses are internationalized. So, these companies are more open and more influenced by the global financial information. Finally, Hong Kong has implemented pegging the US dollars foreign exchange system since 1983 . The market price volatility information, such as interest rate change, foreign exchange rate change and the expected yield changes in equities in the US market will spread out to the Hong Kong market promptly. It is no doubt that these important information releases enhance the role of the NYSE in price discovery.

\section{References}

[1] Fama E. \& K. French. (1988). Permanent and temporary components of stock prices, Journal of Political Economy 96 , 246-273.

[2] Kim, M., A.C. Szakmary \& I. Mathur. (2000). Price transmission dynamics between ADRs and their underlying foreign securities. Journal of Banking and Finance 24, 1359-1382.

[3] Jiang, C.X. (1998). Diversification with American Depository Receipts: the dynamics and the pricing factors. Journal of Business Finance and Accounting 25, 683-699.

[4] Bacidore, J. \& G. Sofianos. (2002). Liquidity provision and specialist trading in NYSE listed non-U.S. stocks. Journal of Financial Economics 63, 133-158.

[5] Alaganar, V.T. \& R., Bhar. (2001). Diversification gains from American Depositary Receipts and foreign equities: evidence from Australian stocks. Journal of International Financial Markets, Institutions and Money 11, 97-113.

[6] Patro, D.K.(2000). Return behavior and pricing of American Depositary Receipts. Journal of International Finance Markets, Institutions and Money 10, 43-67.

[7] Choi, Y.K. \& D. Kim. (2000). Determinants of American Depositary Receipts and their underlying stock returns: implications for international diversification. International Review of Financial Analysis 9, 351-368.

[8] Xu, X.E. \& H.G. Fung (2002). Information flows across markets evidence from China-Backed stocks dually listed in Hong Kong and New York, The Financial Review, 37, 563-588.

[9] Kutan A.M. \& H. Zhou. (2006). Determinants of Returns and Volatility of Chinese ADRs at NYSE. Journal of Multinational Financial Management, 16(1), 1-15.

[10] Su, Q. \& T.T. Chong. (2007). Determining the contributions to price discovery for Chinese cross-listed stocks, Pacific-Basin Finance Journal, 15(2), 140-153.

[11] Gonzalo, J. \& W. J. Granger. (1995). Estimation of common longmemory components in cointegrated systems, Journal of Business \& Economics Statistics 13, 27-36.

[12] Granger C.W.J. \& P. Newbold. (1974). Spurious regressions in econometrics, Journal of Econometrics 2, 111-120.

[13] Dickey, D. \& W. Fuller. (1979). Distribution of the estimators for autoregressive time series with a unit root. Journal of American Statistical Association 74, 427-431. 
[14] Phillips, P. (1986). Understanding spurious regressions in econometrics, Journal of Econometrics 33, 311-340.

[15] MacKinnon, J.G. (1996). Numerical distribution functions for unit root and cointegration tests. Journal of Applied Econometrics 11, 601-618.

[16] MacKinnon, J.G., A.A. Haug \& L. Michelis (1999). Numerical distribution functions of likelihood ratio tests for cointegration. Journal of Applied Econometrics 14, 563-577.

[17] Johansen, S. \& K. Juselius. (1990). Maximum likelihood estimation and inference on cointegration-with application to the demand for money, Oxford Bulletin of Economics and Statistics 52(2), 169-210

[18] Banerjee, A., J.J. Dolado, J.W. Galbraith \& D.F. Hendry (1993). Co-integration, error-correction, and the econometric analysis of non-stationary data, Oxford University Press, Oxford.
[19] Ely, D \& M. Salehizadeh (2001). American depositary receipts: an analysis of international stock price movements, International Review of Financial Analysis 10, 343-363.

[20] Erbaykal, E, H.A. Okuyan \& O. Kadıŏlu. (2008). Cointegration and Priority Relationships between Stock Markets of Turkey, Brazil and Argentina. European Journal of Economics, Finance and Administrative Sciences, 10,151-158.

[21] Fong, K. \& R. Zurbrueggb (2003). How much do locals contribute to the price discovery process? Journal of Empirical Finance 10 (3), 305-320.

[22] Granger, W. J. (1969). Investigating Causal Relations by Econometric Models and Cross-spectral Methods. Econometrica $37,424-438$.

[23] Hasbrouck, J. (1995). One security, many markets: Determining the contributions to price discovery. Journal of Finance 50, 1175-1199. 